scars are also much more soft and supple, and the movements of the arms are very little restricted.

Sheringham.

\section{A NOTE ON TREATMENT BY REFLEX STIMULATION OF THE VAGUS CENTRE.}

By A. T. BRAND, M.D., C.M. ABERD.,

PHYSICIAN, DRIFFIELD HOSPITAL; MEDICAT OFFICER, DRIFFIELD WORKHOUSE INFIRMARY.

Treatuent of morbid conditions by " counter-irritation" dates from time immemorial, but no satisfactory explanation of the rationale of the method has yet been given. I have been experimenting with this method of treatment in several diseases, in which the ordinary text-book treatment has proved futile, with such satisfactory results that the following illustrative cases are recorded in the hope that others may also find benefit from its use on similar occasions.

CASE 1. Exophthalmuc goitre. - Last year a woman, aged 27 years, developed Graves's disease, in wbich the usual symptoms were present-e.g., tremors, tachycardia, feeling of fulness in the throat, and exophthalmos, these two last being, however, slight in degree. There was no anæmia. The most distressing feature in the case was an intractable nausea, which all the usual remedies, including sinapisms over the epigastrium, were powerless to relieve. So great was the gastric irritability that even sips of cold water were rejected, and the patient appeared to be rapidly sinking from inanition. Cocaine was given in half-grain doses in the hope of anæsthetising the peripheral gastric distribution of the vagus, but only slight temporary relief was experienced. At last it occurred to me that if the vagus centre in the medulla could be reflexly influenced a good result might possibly follow. The skin directly over the course of the par vagum in the neck was irritated by applyirg linimentum iodi to an area of the size of a shilling on both sides, immediately behind and below the angle of the lower jaw. As soon as blistering occurred the nausea rapidly subsided and disappeared in a few days, to reappear, though to a less extent, when the blistered parts had healed. Fresh blisters were induced just below the previous ones, when the nausea once more disappeared and never returned. The patient was then able to take and retain food, and $g$ adually put on flesh. Not only was the nausea removed, but the pulse-rate also fell in a week or two from 120-140 per minute to 80 , soon afterwards becoming normal. This result may have been due to the afferent stinulation of the vagus centre causing efferent influences conveyed by the par vagum to the stomach and heart. As soon as the patient could retain food, \&c., she was given thyroidectin (the inspissated blood of a thyroidectomised animal) in 10 grain doses t.d.s., which was continued for six months, and she is now practically well, How much of the recovery is to be credited to the thyroidectin it is impossible to say, but it is obvious that, unless the nausea had been checked, the patient could not possibly have taken a $y$ of it.

CASE 2. Spasmodic asthma.-For the last three years a very refractory case of this disease, a married woman aged 50 years, has been under treatment, which the usual remedies, including a much-vaunted inhalation, were unable to affect. Mor hia alone had any control over the spasmodic attacks; but cure, not merely relief, was the goal aimed at, and, naturally, the routine use of this insidious drug was avoided. Encouraged by the success attending the reflex stimulation of the vagus centre in the previous case, where the gastrocardiac distribution of the vagus was favourably influenced, it was hoped that similar treatment would also influence its distribution to the respiratory system. Blisters were accordingly induced on the skin immediately over the nerve in the neck on both sides as before. The asthma was decidedly relieved, the spasmodic attacks being now not only very much fewer but much less severe when they do occur. The attacks used to last for several hours, but now, when an attack comes on and lin. iodi is painted on the neck over the par vagum until the skin smarts severely, the attack is cat short in half an hour.

Cast 3 Pertussis. - In a case of whooping-cough in a girl, aged 10 years, the paroxysms were exceedingly frequent and violent and the concomitant vomiting so severe that the patient was rapidly becoming emaciated and exhausted. Appetite was good. but food could not be retained long enough to be digest ?d, far less assimilated. It was evident that unless this condition conld be relieved recovery could not be looked for. Again the skin was blistered in exactly the same way over the par vagum, with the result that the paroxysms were at once not only greatly reduced in severity, but the interval between them was so much prolonged that the acts of vomiting became infrequent, food was retained and assimilated, and the child made a rapid recovery.

Nausea and comiting generally. - Not only in reflex nausea and vomiting does stimulation of the vagus centre by blistering over the par vagum prove helpful, but also in cases of pathological conditions of the stomach itself, and I have found it to act much more satisfactorily than sinapisms over the epigastrium and the other usual remedies. No opportunity has yet arisen to try this method of treatment in the vomiting of pregnancy, but analogy leads me to expect similar relief in this condition also.

It seems possible that the vagus centre and its neighbourhood are really influenced, directly or reflexly, by the cutaneous stimulation over the course of the nerve, where it lies so near the surface in the neck, with the result that its peripheral distribution, cardio-pneumo-gastric, is affected, inducing a return to normal conditions of the organs innervated by it. In the absence of definite knowledge recourse may be had empirically to this method of treatment by reflex stimulation of the medulla, since it seems to achieve the end in view. I hope that it will be tried by other physicians. Driffield.

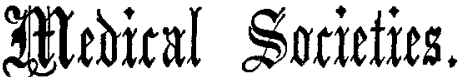

\section{ROYAL SOCIETY OF MEDICINE.}

\section{Resumed Debate on Syphilis.}

Major H. C. FRENCH, R.A.M.C., reopened this discussion on June 24th at considerable length. In his paper he expressed the hope that there would be legislative control of venereal diseases in Britain. He explained that this was not the same thing as the State regulation of vice. He referred to the estimate of Dr. Holland in 1854 that there were 1,500,000 persons infected yearly with syphilis at about the time he wrote (1854), and recently Dr. Mott said that from 3 to 4 per cent. of cases of the disease had subsequently parasypbilitic affections. In New York, out of 300,000 cases of skin disease 11.5 per cent. were syphilitic. In Paris, of every 100 men 15 were said to be syphilitics. The proportion of cases of freshly contracted syphilis in the army, especially in Woolwich and London, was greater than in the army abroad, which he attributed to the lack of control of the disease at its source. Victims of the disease were not segregated, and so the condition was spread broadcast. He thought that from the point of view of public health freshly contracted cases should be distinguished from those in which the disease was relapsing. There had been 3000 victims in 110 epidemics who had contracted the disease innocently; and playing kiss-in-the-ring was answerable for a definite number of cases. In 75 per cent. of cases of syphilis in married women the disease was traceable to the husband. He pointed out the great improvement in the statistics of syphilis in India following the passing of the Cantonment Act of 1897, and considered that that was a good guide for legislative efforts in Britain. With regard to prevention of the disease, in 1896, in answer to a request that the Secretary of State for the Home Department would appoint a Departmental Committee to inquire into the prevalence and treatment of venereal diseases in England, it was said that the Government did not consider the time was ripe for such an inquiry, because public opinion was not sufficiently informed on the matter. Obviously, therefore, it was the duty of the profession to acquaint the public with the true facts. There were a large number of women who, through ignorance, failed to seek treatment for their syphilis. There should be confidential medical notification of the disease, and medical treatment for short periods in hospital in the early and actively contagious stages. He alluded to the fruitf al source of contagion by clandestine prostitution. He had proved in Malta that segregation was very efficacious. He spoke strongly of the need for suppressing the iniquitous " middle man " in prostitution. Uade: the Town Clauses Act of 1847 solicitation and 